\title{
CARBOHYDRATE METABOLISM DISTURBANCES AMONG PUBLIC TRANSPORT DRIVERS - THE NEED FOR REGULATIONS IN POLAND
}

\section{DOROTA SZOSLAND and ANDRZEJ MARCINKIEWICZ}

\author{
Nofer Institute of Occupational Medicine, Łódź, Poland \\ School of Public Health
}

\begin{abstract}
Introduction: The discussion on the relationship between diabetes and driving has continued in recent years all over the world. The issue of diabetes, its treatment models, the risk of hypoglycaemia and license to drive are receiving considerable attention. Driving ability is controlled by specific regulations. Polish legislation does not provide standard procedures for dealing with the question of diabetic drivers and driver candidates. The aim of study was to draw attention to some problems that may emerge when attempting to certify medical fitness of drivers or driver candidate to drive public service vehicles. Materials and Methods: Data were obtained from standardised prophylactic examination forms of public transport drivers employed in a small company between 2001 and 2007. Fasting capillary blood was collected to be analysed with a blood glucose meter. Results: Diabetes and its diagnosing during obligatory preemployement or periodic medical examinations constitutes a serious problem. Abnormal fasting glucose levels were noted in 23 drivers (21.7\%). Discussion: Our study shows that the occupational physician must take into account the possibility of glucose metabolism disturbances. The results demonstrate that an unified approach to diagnosing of diabetes mellitus during such medical examinations is not available currently in Poland. Conclusions: It is necessary to develop standard procedures to be used by occupational physicians for diagnosis diabetes mellitus and intermediate hyperglycaemia. Fasting capillary blood glucose measurement with a blood glucose meter may be used for screening, because it is easier, less expensive and less invasive than venous blood tests. Screening tests must be followed by oral glucose tolerance test using standard criteria in order to make the diagnosis. Frequency of periodic medical assessments in case of diagnosed diabetes mellitus or any intermediate hyperglycaemia must be determined. Specific situations must be identified when the consultation of diabetes specialist is mandatory with respect to therapy, risk of hypoglycaemia and hypoglycaemia awareness.
\end{abstract}

Key words:

Diabetes mellitus, Driving license, Medical certification, Public transport drivers

\section{INTRODUCTION}

The discussion on the relationship between diabetes and driving has continued in recent years all over the world. Type 2 diabetes is a major global health problem. As western lifestyles spread around the world, diabetes has become an epidemic. The number of people with diabetes is expected to double over the 13-year period 1997-2010 as a result of increasing obesity and longevity [1]. The key environmental risk factors for diabetes are known to be insufficient physical exercise, urbanisation and unhealthy diet [2]. It is estimated that currently (2007) 246 million people at the age from 20 to 79 suffer from diabetes and the estimated figure for 2025 is 333 million. World diabetes prevalence is going to rise from $5.1 \%$ in the year 2003 to $6.3 \%$ in 2025 . The number of adults with IGT (impaired glucose tolerance) in 2003 was 314 millions and in 2025 it is estimated to reach 472 millions [3]. The prevalence of impaired glucose metabolism is higher among the men than among the women $[4,5]$.

In Poland, type 2 diabetes affects $90 \%$ of over 2 million patients with diabetes, and approximately one half of the cases remain undiagnosed. The prevalence of diabetes type 2 accounts for $5.37 \%$ [6] and the number of new diagnosed cases is higher in people over 55 [7].

Received: March 26, 2008. Accepted: July 02, 2008.

Address reprint requests to D. Szosland, Nofer Institute of Occupational Medicine, św. Teresy 8, 91-348 Łódź, Poland (e-mail: szosland@imp.lodz.pl). 
The issue of diabetes, its treatment models, the risk of hypoglycaemia and driver's license are receiving considerable attention. Driving by diabetic patients may be impaired not only by hypoglycaemia but by hyperglycaemia and diabetes complications as well [8,9].

Employment in the transportation industries is often regulated by governments, whose ultimate concern is to balance public safety with personal choice, mobility and fairness. Driving ability is controlled by specific regulations. The main potential danger of diabetes and driving is the possibility of hypoglycaemia [10]. Hypoglycaemia occurs from a relative excess of insulin in the blood and results in excessively low blood glucose level. That does not happen in people with diabetes who are treated with diet and exercise and is rare in people treated with biguanides, tiazolidinediones or á-glucosidase inhibitors. When appropriate doses of any oral glucose lowering agents are used to manage blood glucose, severe hypoglycaemia does not occur [11]. Hypoglycaemia is a common side effect of insulin therapy and may present a risk for some occupations [12]. The frequency of hypoglycaemia is lower in type 2 regardless of treatment modality than in type 1 diabetes [13]. Unrecognised hypoglycaemia represents a significant driving hazard. Bus drivers, who have a specific responsibility for the safety of the passengers, may serve as an example of the occupation seriously affecting public safety.

In Europe, many countries have restrictions for diabetic drivers. The European Union has issued directive 91/439/ EEC, called the "Second Directive", on Driving Licenses containing detailed provisions on minimum health criteria and stating that diabetic patients who are using insulin are excluded from driving trucks, heavy goods vehicles, and buses. Except is made for small trucks in "very exceptional cases"[14].

The existing regulations in different countries are based on empirical knowledge and common sense [15].

No standard procedures are available in Polish legislation for dealing with the question of diabetic drivers. The only one that exists is Ministry of Health regulation of January 7, 2004 on the medical evaluation for drivers and people applying for driving license. It states that physicians authorised to certify applicant's ability to drive motor vehicles from the results of interview (Examination Form), medical examination and blood test, is obliged to confirm or exclude diabetes. However, there are no further recommendations on the procedure to be followed in case any impairment is detected [16].

Medical documentation for every employee who has to pass prophylactic examination by an authorised physician (occupational medicine specialist) has been standardised since 1997. The model of prophylactic examination form has been included in Ministry of Health regulation of September 15, 1997 on Occupational Health Services medical documentation.

Authorized physicians are entitled to perform preemployment examination, periodic medical examination or control examination and prophylactic examination form must be filled (according to act of June 26, 1974 Labour Code). The extent of prophylactic activities depends on occupation, the working conditions and health status of the employee. Suitability for employment should be re-assessed.

\section{MATERIALS AND METHODS}

The material consisted of data obtained from medical records of public transport drivers employed between 2001-2007 in a public bus transport company (Miejski Zakład Komunikacji Sp. z 0.o) in Pabianice, a medium-size (76 thousand inhabitants) town in central Poland.

Data from standardised prophylactic examination forms (2001-2007) were analysed. During that period, the company employed 106 drivers.

Fasting capillary blood was collected and analysed with an AccuChek Active blood glucose meter.

Patients with fasting capillary blood glucose (FCBG) level below $100 \mathrm{mg} / \mathrm{dl}(5.5 \mathrm{mmol} / \mathrm{l})$ were considered as nondiabetics. Patients with FCBG level $\geq 200 \mathrm{mg} / \mathrm{dl}$ $(11.1 \mathrm{mmol} / \mathrm{l})$ were considered to be diabetic. Those with FCBG $\geq 100 \mathrm{mg} / \mathrm{dl}$ but $<200 \mathrm{mg} / \mathrm{dl}$ were screened for diabetes according to European Diabetes Policy Group 1998-1999 [17] and WHO 1999 guidelines [18]. These patients were referred for oral glucose tolerance test (OGTT) in an accredited laboratory. 
The criteria used for the diagnosis of diabetes and "prediabetes" (intermediate hyperglycaemia) were based on the Clinical Guidelines of Polish Diabetes Association for the management of diabetes 2008 [19] and American Diabetes Association, Clinical Practice Recommendations 2008 [20].

\section{RESULTS}

The data obtained from standardised prophylactic examination forms for 2001 to 2007 were analysed. The study group included 106 bus drivers, men between 22 and 63 years of age. Their mean age was 44.3.

Table 1. Age groups (men)

\begin{tabular}{lcc}
\hline \multicolumn{1}{c}{ Age (years) } & Number of patients & $\%$ \\
\hline $20-24$ & 1 & 0.94 \\
$25-30$ & 5 & 4.72 \\
$30-34$ & 8 & 7.55 \\
$35-39$ & 16 & 15.09 \\
$40-44$ & 25 & 23.58 \\
$45-49$ & 20 & 18.87 \\
$50-54$ & 18 & 16.98 \\
$55-59$ & 10 & 9.43 \\
$60-65$ & 3 & 2.83 \\
Total & 106 & 100.00 \\
\hline
\end{tabular}

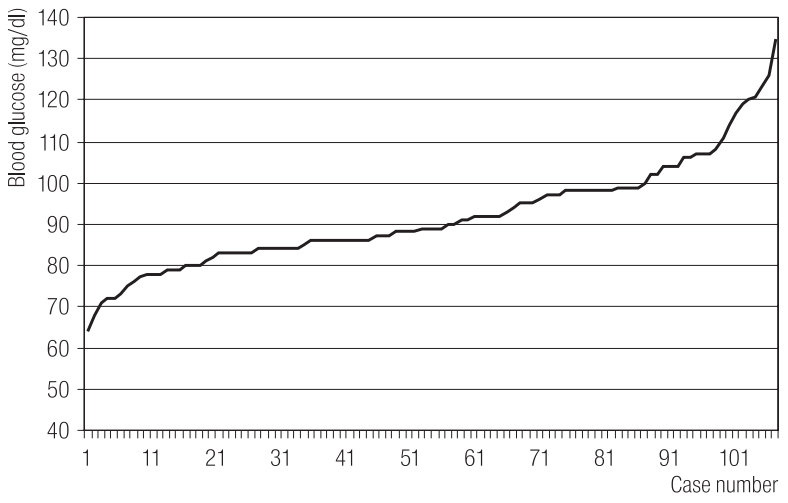

Fig. 1. Fasting glucose concentration distribution.

Fasting capillary blood glucose (FCBG) was measured with an AccuCheck Active blood glucose meter, and the results ranged from $64 \mathrm{mg} / \mathrm{dl}$ to $135 \mathrm{mg} / \mathrm{dl}$.

Figure 1 shows the distribution of the fasting blood glucose concentration among the examined drivers.

According to American Diabetes Association and Polish Diabetes Association recommendations 2008, impaired fasting glucose levels were observed in 23 drivers $(21.7 \%)$.

Two of the examined drivers were diagnosed with diabetes before 2001, 21 examined patients were not aware of their disturbed carbohydrate metabolism.

Several examined drivers were referred to an accredited laboratory for oral glucose tolerance test (OGTT).

Table 2. Normoglycaemia, intermediate hyperglycaemia and diabetes in age groups

\begin{tabular}{|c|c|c|c|c|c|c|c|c|c|c|c|c|}
\hline \multirow{3}{*}{$\begin{array}{c}\text { Age } \\
\text { (years) }\end{array}$} & \multicolumn{8}{|c|}{ Glucose metabolism disturbances } & \multirow{2}{*}{\multicolumn{2}{|c|}{ Normogwlycaemia }} & \multirow{2}{*}{\multicolumn{2}{|c|}{ Total }} \\
\hline & \multicolumn{2}{|c|}{ Hiperglycaemia } & \multicolumn{2}{|c|}{$\begin{array}{l}\text { Impaired glucose } \\
\text { tolerance (IGT) }\end{array}$} & \multicolumn{2}{|c|}{ Diabetes mellitus } & \multicolumn{2}{|c|}{$\begin{array}{l}\text { Total glucose } \\
\text { metabolism } \\
\text { disturbances }\end{array}$} & & & & \\
\hline & $\mathrm{n}$ & $\%$ & $\mathrm{n}$ & $\%$ & $\mathrm{n}$ & $\%$ & $\mathrm{n}$ & $\%$ & $\mathrm{n}$ & $\%$ & $\mathrm{n}$ & $\%$ \\
\hline $20-24$ & 0 & 0.00 & 0 & 0.00 & 0 & 0.00 & 0 & 0.00 & 1 & 100.00 & 1 & 100 \\
\hline $25-29$ & 0 & 0.00 & 0 & 0.00 & 0 & 0.00 & 0 & 0.00 & 5 & 100.00 & 5 & 100 \\
\hline $30-34$ & 2 & 25.00 & 0 & 0.00 & 0 & 0.00 & 2 & 25.00 & 6 & 75.00 & 8 & 100 \\
\hline $35-39$ & 0 & 0.00 & 1 & 6.25 & 0 & 0.00 & 1 & 6.25 & 15 & 93.75 & 16 & 100 \\
\hline $40-44$ & 3 & 12.00 & 2 & 8.00 & 1 & 4.00 & 6 & 24.00 & 19 & 76.00 & 25 & 100 \\
\hline $45-49$ & 4 & 20.00 & 0 & 0.00 & 0 & 0.00 & 4 & 20.00 & 16 & 80.00 & 20 & 100 \\
\hline $50-54$ & 3 & 16.67 & 0 & 0.00 & 2 & 11.11 & 5 & 27.78 & 13 & 72.22 & 18 & 100 \\
\hline $55-59$ & 2 & 20.00 & 0 & 0.00 & 1 & 10.00 & 3 & 30.00 & 7 & 70.00 & 10 & 100 \\
\hline $60-64$ & 2 & 66.67 & 0 & 0.00 & 0 & 0.00 & 2 & 66.67 & 1 & 33.33 & 3 & 100 \\
\hline Total & 16 & 15.09 & 3 & 2.83 & 4 & 3.77 & 23 & 21.70 & 83 & 78.30 & 106 & 100 \\
\hline
\end{tabular}


Table 3. Case history of diagnosis of impaired glucose tolerance

\begin{tabular}{|c|c|c|c|c|c|c|}
\hline \multirow[b]{2}{*}{ Year } & \multicolumn{2}{|c|}{ Driver 1 (44 years) } & \multicolumn{2}{|c|}{ Driver 2 (43 years) } & \multicolumn{2}{|c|}{ Driver 3 (39 years) } \\
\hline & $\begin{array}{l}\text { Fasting blood } \\
\text { glucose (gluco- } \\
\text { meter, mg/dl) }\end{array}$ & $\begin{array}{c}\text { Oral glucose } \\
\text { tolerance test } \\
\text { (OGTT) }(\text { accredited } \\
\text { laboratory, } \mathrm{mg} / \mathrm{dl})\end{array}$ & $\begin{array}{l}\text { Fasting blood } \\
\text { glucose (gluco- } \\
\text { meter, mg/dl) }\end{array}$ & $\begin{array}{c}\text { Oral glucose } \\
\text { tolerance test } \\
\text { (OGTT) (accredited } \\
\text { laboratory, } \mathrm{mg} / \mathrm{dl}) \\
\end{array}$ & $\begin{array}{l}\text { Fasting blood } \\
\text { glucose (gluco- } \\
\text { meter, mg/dl) }\end{array}$ & $\begin{array}{c}\text { Oral glucose } \\
\text { tolerance test } \\
(\text { OGTT) }(\text { accredited } \\
\text { laboratory, mg/dl) }\end{array}$ \\
\hline 2003 & 108 & - & 100 & - & - & - \\
\hline 2004 & 82 & - & - & - & 81 & - \\
\hline 2005 & 92 & $\begin{array}{l}\text { Fasting plasma } \\
\text { glucose - } 94 \\
\text { 2-h plasma } \\
\text { glucose }-116\end{array}$ & - & - & - & - \\
\hline 2006 & 91 & - & 117 & $\begin{array}{l}\text { Fasting plasma } \\
\text { glucose }-120 \\
\text { 2-h plasma } \\
\text { glucose }-169\end{array}$ & - & - \\
\hline 2007 & 98 & $\begin{array}{l}\text { Fasting plasma } \\
\text { glucose }-114 \\
\text { 2-h plasma } \\
\text { glucose }-150\end{array}$ & 120 & - & 120 & $\begin{array}{l}\text { Fasting plasma } \\
\text { glucose }-117 \\
\text { 2-h plasma } \\
\text { glucose }-147\end{array}$ \\
\hline
\end{tabular}

Table 2 presents glucose metabolism disturbances in examined group of drivers.

Two patients were diagnosed as diabetics since regular medical examination had started, on the basis of the oral glucose tolerance test (OGTT).

"Pre-diabetes" in the form of impaired glucose tolerance was diagnosed in 3 individuals (Table 3 ).

No further diagnosis was carried out in 14 drivers with fasting capillary blood glucose ranging from 100 to $111 \mathrm{mg} / \mathrm{dl}$.

All of 4 diagnosed diabetic public transport drivers are treated with oral drugs: 3 with biguanides, one with the combination of biguanide and third generation of sulphonylureas. None of them takes insulin. All patients monitor blood glucose, and hypoglycaemia has never occurred.

\section{DISCUSSION}

Having analysed data from standardised prophylactic examination forms of public transport drivers employed in a small company, we have found that diabetes and its diagnosis during performing obligatory preemployement or periodic medical examination continues to be a problem.
The results demonstrate that there is no unified approach to diagnosing of diabetes mellitus during such medical examinations in Poland. Some drivers with fasting capillary blood glucose between 100 and $111 \mathrm{mg} / \mathrm{dl}$ were left without further diagnosis. Medical review before licensing and afterwards at strictly determined time intervals is necessary. In order to screen out individuals who would present a significant risk, it is necessary that a routine medical history and physical examination be used to identify persons with diabetes. The decision should be made on an individual basis.

The aim of our study was to highlight some problems that may emerge in certifying medical fitness to drive a public service vehicles used for transport of people.

Some countries in European Union have their own regulatory system which screens applicants for medical suitability [15]. The standard of fitness required from a professional driver is generally higher than that required from a private car driver. Some type of standardisation should be established between the member nations of European Union regarding licensing.

A European Commission medical expert working group has been considering the minimum medical standards for diabetes and driving. This group has been working since 2004 . 
A Report of the Second European Working Group on Diabetes and Driving, an advisory board to the Driving License Committee of the European Union was published on line in 2006 [21]. The report gives some remarks, comments and suggestions for the future. At the present moment, this report has the status of a working document.

\section{CONCLUSIONS}

Our results show that, even though the people permitted to drive buses are selected from among healthy population (drivers must hold group 2 driving license), the occupational physician must take into account the risk of possible glucose metabolism disturbances.

That is why it is the necessary to set up standard procedures to be followed by occupational physicians:

1. Diagnosing diabetes mellitus and intermediate hyperglycaemia.

- Fasting capillary blood glucose measured with a blood glucose meter may be used for screening, because it is easier, less expensive and less invasive to obtain than venous blood [22,23]. A high correlation between capillary and venous plasma glucose values was found during fasting and at 2 hours post load [23].

- Screening tests must be followed by oral glucose tolerance test (OGTT) using standard criteria in order to make the diagnosis.

2. Procedures to be used in case of diagnosed impairment in blood glucose metabolism.

- It is not appropriate that 14 people with capillary fasting blood glucose between 100 and $111 \mathrm{mg} / \mathrm{dl}$ in this report had been left without further diagnosis.

3. Frequency of periodic medical assessment in case of diagnosed diabetes mellitus or any intermediate hyperglycaemia must be determined.

4. Specific situations must be defined when the consultation of diabetes specialist on the required therapy, risk of hypoglycaemia and hypoglycaemia awareness is mandatory.

\section{REFERENCES}

1. Amos AF, McCarthy DJ, Zimmet P. The rising global burden of diabetes and its complications: estimates and projections to the year 2010. Diabet Med 1997;14(Suppl 5):S1-S85.

2. Wild S, Roglic G, Green A. Global Prevalence of Diabetes. Estimates for the year 2000 and projections for 2030. Diabetes Care 2004;27:1047-53.

3. Diabetes Altas Second Edition. (cited 2008 February 20) Available from: http:/www.eatlas.idf.org/webdata/docs/ Atlas\%202003-Summary.pdf.

4. Kuhl J, Hilding A, Ostenson, Grill V, Efendic S, Bavenholm P. Characterisation of subjects with early abnormalities of glucose tolerance in the Stockholm Diabetes Prevention Programme: The impact of sex and type 2 diabetes heredity. Diabetologia 2005;48:35-40.

5. Almdal T, Scharling H, Jensen JS, Vestergaard H. Higher prevalence of risk factors for type 2 diabetes mellitus and subsequent higher incidence in men. E J Intern Med 2008;19(1):40-5.

6. Szybiński Z. Polish Multicenter Study on Diabetes Epidemiology (PMSDE) - 1998-2000. Pol Arch Med Wewn 2001;106(3):751-8 [in Polish].

7. Szurkowska M, Szafraniec K, Gilis-Januszewska A, Pach D, Krzentowska A, Szybiński Z, et al. Prevalence of the glucose metabolizm disturbances in screening of adult inhabitans of Krakow. Przegl Lek 2006;63(9):728-32 [in Polish].

8. Cox DJ, Kovatchew BP, Gonder-Frederick LA, Summers KH, McCall A, Grimm KJ, Clarke WL. Relationships between hyperglycaemia and cognate performance among adults with type 1 and type 2 diabetes. Diabetes Care 2005;28:71-7.

9. Sommerfield AJ, Deary IJ, Frier BM. Acute hyperglycemia alters mood state and cognitive performance in people with type 2 diabetes. Diabetes Care 2004;27:2335-40.

10. Harsh IA, Stocker S, Radespiel-Troger M, Hahn EG, Konturek PC, Ficker JH, et al. Traffic hypoglycaemias and accidents in patients with diabetes mellitus treated with different antidiabetic regimens. J Int Med 2002;252(4):352-60.

11. Cryer PE, Davis SN, Shamoon H. Hypoglycaemia in diabetes. Diabetes Care 2003;26:1902-12.

12. Leckie AM, Graham MK, Grant JB, Ritchie PJ, Frier BM. Frequency, severity, and morbidity of hypoglycaemia occurring in the workplace in people with insulin treated diabetes. Diabetes Care 2005;28:1333-8. 
13. Zammitt NN, Frier BM. Hypoglycaemia in type 2 diabetes. Pathophysiology, frequency and effects of different treatment modalities. Diabetes Care 2005;28:2948-61.

14. Council Directives on Driving Licenses 91/439/EEC OJ-L237 (1991 August 24).

15. Marcinkiewicz A, Szosland D. Medical certification for diabetic drivers in the selected European Union member states. Med Pr 2007;58(6):541-6 [in Polish].

16. Chromińska-Szosland D, Marcinkiewicz A. Diabetes mellitus as an issue for medical certification. Med $\operatorname{Pr}$ 2006;57(5):469-4 [in Polish].

17. A desktop guide to type 2 diabetes. European Diabetes Policy Group 1999. Diabet Med 1999;16(9):716-30.

18. World Health Organization. Definition, diagnosis and classification of diabetes mellitus and its complications. Report of WHO consultation. Part 1. Diagnosis and classification of diabetes mellitus. Geneva: WHO; 1999.

19. Polish Diabetes Association. Clinical guidelines for the management of diabetes 2008. Diabetologia Prakt 2008;9 (Suppl A):A1-A49 [in Polish].
20. American Diabetes Association. Clinical Practice Recommendations 2008. Diabetes Care 2008;31(Suppl A):A55-60.

21. Diabetes and Driving In Europe. A Report of Second European Working Group on Diabetes and Driving, an advisory board to the Driving License Committee of the European Union (cited 2008 March 10). Available from: http://ec.europa.eu/ transport/roadsafety/behavior/doc/diabetes_and_driving _ in_europe_final_1.pdf.

22. Screening for Type 2 Diabetes. Report of a WHO and IDF meeting. WHO Department of Noncommunicable Disease Management (cited 2008 August 20). Available from: http:// www.who.int/diabetes/publications/en/screening_mnc03. pdf.

23. Kruijshoop M, Feskens EJM, Blaak EE, de Bruin TWA. Validation of capillary glucose measurements to detect intolerance or type 2 diabetes mellitus in the general population. Clin Chim Acta 2004;341:33-40. 